\title{
Review: group psychotherapy is effective for depression
}

McDermut W,Miller IW,Brown RA. The efficacy of group psychotherapy for depression: a meta-analysis and review of the
empirical research. Clinical Psychology: Science and Practice 2001 Spring;8:98-116.

\section{QUESTION: Is group psychotherapy effective for patients with depression?}

\section{Data sources}

Studies were identified by searching PsycLIT and Medline with the terms group, therapy, and depression. Reference lists were scanned and recent issues of relevant psychology and psychiatry journals were handsearched.

\section{Study selection}

English language studies published from 1970-98 were selected if they tested the efficacy of group psychotherapy for depressive spectrum disorders in adults, used well known self report or interviewer based measures of depression, and reported pre-treatment and post-treatment scores on depression measures for participants assigned to group therapy. Case studies were excluded.

\section{Data extraction}

Data were extracted on diagnostic criteria, inclusion and exclusion criteria, depression measures, and results. Effect sizes were calculated for each study.

\section{Main results}

48 studies met the selection criteria. The patients' mean age was 44 years, and $70 \%$ of patients were women. 18 studies included an untreated control group. All but 1 study included a cognitive and/or behavioural treatment group. 8 of 12 studies that compared cognitive behavioural therapy with a non-cognitive behavioural intervention included psychodynamic or interpersonally oriented group therapy. 45 of the 48 studies reported that group psychotherapy was effective for reducing depressive symptoms. 43 studies showed statistically significant decreases in depressive symptoms for group psychotherapy, and 2 studies did not report statistical analyses. The pooled results showed that group psychotherapy was more effective than no treatment after the treatment period (15 studies) and at a mean 19.1 weeks after treatment ended (10 studies) (table). 9 studies showed that group psychotherapy and individual psychotherapy did not differ in effectiveness (table). 8 studies showed that cognitive behavioural therapy was more effective than psychodynamic group therapy (table).

\section{Conclusion}

In patients with depression, group psychotherapy is effective for relieving symptoms.

\section{COMMENTARY}

The meta-analysis by McDermut et al provides a timely and comprehensive review of group treatments for depression that mirrors the conclusions of other more general meta-analyses of group therapy.

The meta-analytic methodology is sound and provides summary conclusions over a broad range of studies with salient clinical implications. First and foremost, clinicians can be assured that group depression treatment has substantial empirical support. Secondly, for clients who want group therapy, it may be as effective as individual therapy. Finally, for clinicians trying to decide whether to focus on process oriented groups or more structured psychoeducational groups, this meta-analysis provides modest support for the superiority of the latter.

Although these summary findings provide some general guidance for clinicians, they do not provide specific information regarding matching clients to treatments. McDermut $e t$ al note that although little existing research has addressed these questions, methodological artefacts, as well as targeted findings, point to some clinical recommendations. Firstly, only clients who are enthusiastic about the group modality should be assigned to group treatment because (1) the most common reason for attrition in $\geqslant 2$ studies was dissatisfaction with group modality; and (2) all participants in all studies were volunteers agreeing to participate in group therapy. Secondly, because severely depressed, suicidal, or comorbid clients were often excluded from the research samples, little is known about the effectiveness of group treatment with this population. In addition, more severe clients may require "a strong dose" of therapy to reach recovery. ${ }^{2}$ Thus, group therapy may be most efficacious as an adjunct to individual treatment and medication for more severe depression.

In sum, group depression treatment appears to be an adequate alternative to individual therapy for mild to moderately depressed clients receptive to group treatments.

Paula Truax, $\mathrm{PhD}$

Pacific University Portland, Oregon, USA

1 McRoberts C, Burlingame GM, Hoag MJ. Comparative efficacy of individual and group psychotherapy: a metaanalytic perspective. Group Dynamics 1998;2:101-17.

2 Kopta SM, Howard KI, Lowry JL, et al. Patterns of symptomatic recovery in psychotherapy. I Consult Clin Psychol 1994;62:1009-16.
Source of funding: in part, National Alliance for Research on Schizophrenia and Depression Young Investigator Award to Wilson McDermut.

For correspondence: Dr W McDermut, Department of Psychology, William Paterson University, 300 Pompton Road, Wayne, NJ 07470, USA.
Group psychotherapy for relieving depressive symptoms in patients with depression*

\begin{tabular}{llll} 
Comparison & $\begin{array}{l}\text { Number of } \\
\text { studies }\end{array}$ & $\begin{array}{l}\text { Mean effect size } \\
(95 \% \text { Cl) }\end{array}$ & $\begin{array}{l}\text { Number of control } \\
\text { patients with worse } \\
\text { outcome† }\end{array}$ \\
Group psychotherapy $v$ no treatment at post-treatment & 15 & $1.03(0.6$ to 1.5$)$ & $85 \%(72$ to 93$)$ \\
\hline Group psychotherapy $v$ no treatment at mean 19.1 weeks after treatment & 10 & $1.2(0.6$ to 1.8$)$ & $88 \%(72$ to 96$)$ \\
\hline Group $v$ individual psychotherapy & 9 & -0.2 (not significant) & Not significant \\
\hline CBT $v$ psychodynamic group therapy & 8 & $0.3(0.0$ to 0.6$)$ & $62 \%(50$ to 72$)$ \\
\hline
\end{tabular}

${ }^{*} \mathrm{CBT}=$ cognitive behavioural therapy.

†Proportion of patients in the control group with a worse outcome than the average patient in the treatment group; see glossary. 